\title{
Emodin induces human $T$ cell apoptosis in vitro by ROS-mediated endoplasmic reticulum stress and mitochondrial dysfunction
}

\author{
Kai QU ${ }^{1, \#}$, Nai-ying SHEN ${ }^{2, \#}$, Xin-sen XU ${ }^{1}$, Hai-bo SU ${ }^{1}$, Ji-chao WEI ${ }^{1}$, Ming-hui TAI ${ }^{1}$, Fan-di MENG ${ }^{1}$, Lei ZHOU ${ }^{1}$, Yue-lang \\ ZHANG ${ }^{3}$, Chang LIU $^{1, *}$ \\ ${ }^{1}$ Department of Hepatobiliary Surgery, The First Affiliated Hospital of Medical College, Xi'an Jiaotong University, Xi'an 710061, China; \\ ${ }^{2}$ Department of General Surgery, Shaanxi Nuclear Geology 215 Hospital, Xianyang 712000, China; ${ }^{3}$ Department of Imaging, The First \\ Affiliated Hospital of Medical College, Xi'an Jiaotong University, Xi'an 710061, China
}

Aim: To elucidate the molecular mechanisms underlying the immunosuppressive effects of emodin isolated from Rheum palmatum L. Methods: Human T cells were isolated from the peripheral venous blood of 10 healthy adult donors. Cell viability was analyzed with MTT assay. AO/EB and Annexin V/PI staining and DNA damage assay were used to detect cell apoptosis. Fluorescence staining was used to detect the levels of ROS, the mitochondrial membrane potential and intracellular $\mathrm{Ca}^{2+}$. Colorimetry was used to detect the levels of MDA and total SOD and GSH/GSSG ratio. The expression and activity of caspase-3, -4 , and -9 were detected with Western blotting and a fluorometric assay. Western blotting was also used to detect the expression of $\mathrm{Bcl}-2$, Bax, cytochrome $\mathrm{C}$, and endoplasmic reticulum (ER) markers.

Results: Emodin (1, 10, and $100 \mu \mathrm{mol} / \mathrm{L})$ inhibited the growth of human T cells and induced apoptosis in dose- and time-dependent manners. Emodin triggered ER stress and significantly elevated intracellular free $\mathrm{Ca}^{2+}$ in human $\mathrm{T}$ cells. It also disrupted mitochondrial membrane potential, and increased cytosolic level of cytochrome C, and the levels of activated cleavage fragments of caspase-3, -4 , and -9 in human T cells. Furthermore, emodin significantly increased the levels of ROS and MDA, inhibited both SOD level and GSH/ GSSG ratio in human T cells, whereas co-incubation with the ROS scavenger N-acetylcysteine (NAC, 20 umol/L) almost completely blocked emodin-induced ER stress and mitochondrial dysfunction in human T cells, and decreased the caspase cascade-mediated apoptosis.

Conclusion: Emodin exerts immunosuppressive actions at least partly by inducing apoptosis of human T cells, which is triggered by ROS-mediated ER stress and mitochondrial dysfunction.

Keywords: emodin; immunosuppressant; T cell; apoptosis; caspase; intracellular $\mathrm{Ca}^{2+}$; reactive oxygen species; endoplasmic reticulum stress; mitochondrial dysfunction; N-acetylcysteine

Acta Pharmacologica Sinica (2013) 34: 1217-1228; doi: 10.1038/aps.2013.58; published online 1 Jul 2013

\section{Introduction}

An intense inflammatory process is a characteristic pathologic feature of transplant rejection. Therefore, an understanding of immune rejection mechanisms provides the basis for novel immunosuppressive therapies. There is now convincing evidence that $\mathrm{T}$ cells and their secreted cytokines are involved in the inflammatory process. The blockade of $\mathrm{T}$ cell activation and proliferation and consequential cytokine production is one of the main anti-immune rejection principles ${ }^{[1]}$. Molecules

\footnotetext{
\#These authors contributed equally to this work.

* To whom correspondence should be addressed.

E-mail liuchangdoctor@163.com

Received 2013-02-20 Accepted 2013-04-12
}

such as FK $506^{[2]}$, cyclosporine $\mathrm{A}^{[3]}$, and rapamycin ${ }^{[4]}$ have been shown to have immunosuppressive activity by mediating the apoptotic death of activated T cells. However, the quest to identify novel therapeutic compounds for immunosuppressive treatment is a never-ending venture. Plant-derived natural products occupy an important position in the area of immunosuppression.

Emodin (1,3,8-trihydroxy-6-methylanthraquinone) is an effective component isolated from the root and rhizome of the Rheum palmatum plant. It is well known for its physiological antipyretic and anti-inflammatory activities ${ }^{[5,6]}$. Although it has been widely utilized in Chinese medicines to alleviate tissue inflammation ${ }^{[7]}$, there has been scarce evidence to prove its immunopharmacological activity. 
In our previous study, we found that emodin prolonged the mean survival time of skin grafts and decreased the serum IL-2 level in a skin transplantation mouse model, suggesting the potential immunosuppressive activity of emodin ${ }^{[8]}$. Here, we report that in human $\mathrm{T}$ cells, emodin exhibited significant cytotoxicity that was associated with reactive oxygen speciesmediated endoplasmic reticulum stress and mitochondrial dysfunction.

\section{Materials and methods Reagents and antibodies}

Emodin (purity $>99 \%$, obtained from Sigma Chemical Co, St Louis, USA) was dissolved at a concentration of $1 \mathrm{mmol} / \mathrm{L}$ in $100 \%$ dimethylsulfoxide (DMSO) as a stock solution, stored at $-20^{\circ} \mathrm{C}$, and diluted with medium before each experiment. 5,5',6,6' 'tetrachloro-1,1',3,3' 'tetra-ethylbenzimidazolcarbocyanine iodide (JC-1) was purchased from Keygen Biotechnology (Nanjing, China). 3-(4,5-Dimethylthiazol-2-yl)-2,5-diphenyltetrazolium bromide (MTT), 5-(and-6)-carboxy-2', $7^{\prime}$-dichlorofluorescin diacetate (carboxy-DCFDA) and N-acetylcysteine (NAC) were obtained from Sigma(St Louis, MO, USA). Annexin V-FITC/PI was obtained from Beijing Biosea Biotechnology Co, Ltd (Beijing, China). Antibodies against Bcl-2, Bax, Cyt c, COX IV and $\beta$-actin were obtained from Santa Cruz Biotechnology (Santa Cruz, CA, USA). Anti-caspase-3, -4, -8, and -9 antibodies were purchased from Cell Signaling Technology (Beverly, MA, USA). Detection kits for caspase-3, -4, and -9 activity and a malondialdehyde assay kit were obtained from Beyotime Institute of Biotechnology (Nantong, China). A human $\mathrm{T}$ cell enrichment column kit was purchased from R\&D Systems (Minneapolis, MN, USA). All other chemicals were purchased from Sigma (St Louis, MO, USA).

\section{Human T cell purification and activation}

Peripheral blood mononuclear cells (PBMCs) were isolated with Ficoll-Hypaque density gradients from the peripheral venous blood of ten healthy adult donors according to the manufacturer's instructions. Ethical approval was obtained from the ethics committee of the First Affiliated Hospital, Xi'an Jiaotong University. Cells were washed twice in phosphatebuffered solution (PBS), and the cellular concentration was adjusted to $1.0 \times 10^{6} / \mathrm{mL}$. Cell viability was detected with the Trypan blue dye exclusion method. $\mathrm{CD}^{+} \mathrm{T}$ cells were negatively isolated using magnetic beads (R\&D Systems). T cells were then pre-coated with anti-CD3 $(5 \mu \mathrm{g} / \mathrm{mL})$ and anti-CD28 $(1 \mu \mathrm{g} / \mathrm{mL})$ in culture wells as previously described ${ }^{[9-11]}$. For activation, human $\mathrm{T}$ cells were treated with $1 \mathrm{mg} / \mathrm{mL}$ PHA for $24 \mathrm{~h}$, washed, and subsequently cultured in RPMI-1640 medium (Gibco, Carlsbad, CA, USA). Supplemented with $10 \%$ fetal bovine serum (FBS, Hyclone, Logan, UT, USA).

\section{MTT assay for cell viability}

Human T cells $\left(5.0 \times 10^{4}\right.$ cells/well) were seeded in 96-well plates and incubated with emodin at various concentrations $(0,1,10$, or $100 \mu \mathrm{mol} / \mathrm{L})$ for 24,48 , or $72 \mathrm{~h}$ at $37^{\circ} \mathrm{C}$. Then, 20 $\mu \mathrm{L}$ of MTT solution ( $5 \mathrm{~g} / \mathrm{L})$ was added to each well and incu- bated for another $4 \mathrm{~h}$. Supernatants were removed, and formazan crystals were dissolved in $200 \mu \mathrm{L}$ DMSO. Finally, the optical density was determined at $490 \mathrm{~nm}$ using a POLAR star OPTIMA microplate reader (BMG Lab Technologies, Ortenberg, Germany).

\section{AO/EB double staining}

Cells were collected in $10-\mathrm{mL}$ centrifuge tubes at a concentration of $1 \times 10^{6} / \mathrm{mL}$ and centrifuged at $1500 \mathrm{r} / \mathrm{min}$ for $15 \mathrm{~min}$ at room temperature. The cells were then washed with incubation buffer before centrifugation at $1500 \mathrm{r} / \mathrm{min}$ for another $10 \mathrm{~min}$. The cells were resuspended in $100 \mu \mathrm{L}$ of labeling solution and incubated for $15 \mathrm{~min}$ at room temperature in the dark. Subsequently, the cells were centrifuged at $1500 \mathrm{r} / \mathrm{min}$ for $10 \mathrm{~min}$ at room temperature. Eventually, $25 \mu \mathrm{L}$ of the cell suspension $\left(1 \times 10^{6}\right.$ cells $\left./ \mathrm{mL}\right)$ was incubated with $1 \mu \mathrm{L}$ of $\mathrm{AO} /$ EB solution and examined under a fluorescence microscope using a fluorescein filter and a $40 \times$ objective.

\section{Annexin V/PI apoptosis assay}

Pelleted cells were collected and incubated with $5 \mu \mathrm{L}$ Annexin $\mathrm{V}$ and $10 \mu \mathrm{L}$ PI solution at room temperature for $20 \mathrm{~min}$ in the dark. Cellular apoptosis was detected with flow cytometry at an excitation wavelength of $488 \mathrm{~nm}$. FITC fluorescence was detected at a wavelength of $515 \mathrm{~nm}$, and PI was detected at a wavelength of $560 \mathrm{~nm}$.

\section{DNA damage assay}

DNA damage was assessed using the alkaline single-cell gel electrophoresis assay (comet assay). After the emodin treatments mentioned above, cells were incubated in normal medium for $3 \mathrm{~h}$, mixed with low-melting agarose and fixed onto slides. Subsequently, the cells were lysed, and DNA was denatured using an alkaline $(\mathrm{pH}>14)$ solution at $4{ }^{\circ} \mathrm{C}$. Slides were then placed on a horizontal electrophoresis device, stained with ethidium bromide, and visualized by fluorescence microscopy. The results were analyzed with Komet 5 comet assay analysis software, which quantitatively determines the extent of DNA damage in each sample using the mean olive tail moment calculation, which was determined for 50 cells from each group.

\section{Caspase activity assay}

Caspase-3, -4, and -9 activities were analyzed using a caspase apoptosis detection kit according to the manufacturer's instructions. In brief, cells $\left(1 \times 10^{6}\right)$ were pelleted by centrifugation, washed twice with PBS and incubated in $500 \mu \mathrm{L}$ lysis buffer on ice for $10 \mathrm{~min}$. Then, $1 \times$ reaction buffer and $10 \mu \mathrm{L}$ caspase-3 (DEVD-AFC), caspase-4 (LEVD-AFC), or caspase-9 (IEVD-AFC) substrate was added to lysis buffer. The reaction mixtures were incubated at $37^{\circ} \mathrm{C}$ for $60 \mathrm{~min}$. The activities of caspase-3, -4 , and -9 were measured with spectrofluorometry.

\section{Reactive oxygen species assay}

2',7'-Dichlorodihydrofluorescein diacetate (DCFH-DA, Sigma) was used for ROS measurement. DCFH-DA is cleaved intrac- 
ellularly with nonspecific esterases and converted into highly fluorescent $2^{\prime}, 7^{\prime}$-dichlorofluorescein (DCF) upon oxidation by ROS. DCFH-DA working solution was added directly to the medium to reach $10 \mu \mathrm{mol} / \mathrm{L}$ and incubated at $37^{\circ} \mathrm{C}$ for $15 \mathrm{~min}$. The cells were then washed with PBS once and kept on ice for immediate DCF detection with flow cytometry.

\section{Reduced and oxidized glutathione assay}

Cells were trypsinized after drug treatment for $1 \mathrm{~h}$ and prepared according to the instructions of the GSH/GSSG Ratio Assay Kit (Calbiochem, San Diego, CA, USA). Briefly, for the GSSG sample, the thiol-scavenging reagent 1-methyl-2vinylpyridinium trifluoromethanesulfonate was immediately mixed with the cell suspension to eliminate GSH. The cells were frozen and thawed and subsequently extracted with metaphosphoric acid. The cell lysates were added to GSSG or GSH assay buffer. The samples were mixed sequentially with the chromogen 5,5'-dithiobis-2-nitrobenzoic acid, glutathione reductase, and NADPH. The absorbance at $412 \mathrm{~nm}$ was recorded for $3 \mathrm{~min}$, the reaction rate was determined, and the $\mathrm{GSH} / \mathrm{GSSG}$ ratio was obtained [ratio=(GSH-2GSSG)/GSSG].

\section{Malondialdehyde and total superoxide dismutase assay}

The MDA concentration, a marker of lipid peroxidation, was measured with a colorimetric commercial kit (Malondialdehyde Assay kit). Briefly, treated T cells were harvested, and cellular extracts were prepared with sonication in icecold buffer. After centrifugation at $10000 \times g$ for $20 \mathrm{~min}$, the supernatant was measured spectrophotometrically at $532 \mathrm{~nm}$. The MDA level was then normalized to milligram protein, as previously described ${ }^{[12]}$. SOD is one of the most important antioxidative enzymes ${ }^{[13]}$ and its activity was measured with a colorimetric assay kit according to the manufacturer's protocol. Briefly, SOD activity was measured using $100 \mu \mathrm{g}$ of the total protein extract from the emodin-treated human $\mathrm{T}$ cells. Absorbance values were measured spectrophotometrically at $450 \mathrm{~nm}$.

\section{Intracellular calcium measurement}

Human $\mathrm{T}$ cells were loaded with $5 \mathrm{mmol} / \mathrm{L}$ fluo-3-acetoxymethyl ester (Fluo-3-AM) at $37^{\circ} \mathrm{C}$ for $30 \mathrm{~min}$. The cells were then resuspended in $\mathrm{Ca}^{2+}$-free medium without phenol red to a concentration of $4 \times 10^{6}$ cells $/ \mathrm{mL}$. In each experiment, $0.5 \mathrm{~mL}$ of cell suspension was equilibrated with an equal volume of $2 \mathrm{mmol} / \mathrm{L} \mathrm{Ca}^{2+}$-containing medium at $37^{\circ} \mathrm{C}$. The cells were incubated with $2.0 \mathrm{~mL}$ of $0.1 \%$ DMSO or emodin $(1,10$, or 100 $\mu \mathrm{mol} / \mathrm{L})$, and the fluorescent activity was recorded at $\mathrm{Ex}=488$ $\mathrm{nm}$ and Em=515 nm using an MRC-1000 Laser Scanning Confocal Imaging System (Bio-Rad Laboratories, Berkeley, CA, USA).

\section{Mitochondrial membrane potential assay}

After being cultured for $48 \mathrm{~h}$, T cells were collected in 0.5 $\mathrm{mL}$ medium and incubated with $0.5 \mathrm{~mL}$ JC-1 (Sigma) working solution. Cells were incubated at $37^{\circ} \mathrm{C}$ and $5 \% \mathrm{CO}_{2}$ in a humidified incubator for $30 \mathrm{~min}$. The cells were centrifuged at
$1000 \mathrm{r} / \mathrm{min}$ for $3 \mathrm{~min}$ at $4{ }^{\circ} \mathrm{C}$ and washed twice with JC- 1 buffer solution. The mitochondrial membrane potential $(\Delta \Psi \mathrm{m})$ of cells was detected with flow cytometry.

\section{Western blot analysis}

Cells were exposed to various concentrations of emodin and lysed in RIPA buffer (Beyotime Inc, Nantong, China). The protein concentration was determined with the Bradford reagent (Beyotime Inc, haimen, China). Equal amounts of total proteins were separated and transferred to a polyvinylidene difluoride membrane (Millipore, Bedford, MA, USA). The membranes were subsequently immunoblotted with the appropriate primary and secondary antibody (Santa Cruz Biotechnology, Dallas, TX, USA) according to our previous report ${ }^{[14]}$. Signals were detected using an ECL Kit (Pierce, Rockford, IL, USA).

\section{Statistical analysis}

All data were expressed as the mean \pm standard deviations and analyzed with SPSS (Statistical Package for the Social Sciences) 13.0 software (SPSS Inc, Chicago, IL, USA). The samples of each group were compared using an analysis of variance, and multiple comparisons between groups were performed using Student's $t$-test. Values of $P<0.05$ or $P<0.01$ were considered statistically significant.

\section{Results}

Emodin inhibited the growth of human T cells in a dose- and time-dependent manner

Initially, the cytotoxicity of emodin at different doses $(1,10$, and $100 \mu \mathrm{mol} / \mathrm{L}$ ) was investigated in human T cells. Morphological changes, including cytoplasmic shrinkage and apoptotic bodies, were observed in $\mathrm{T}$ cells treated with emodin for $72 \mathrm{~h}$ (Figure 1A). The cell number was significantly decreased in $100 \mu \mathrm{mol} / \mathrm{L}$ emodin-treated T cells. After treatment with different doses of emodin, the MTT assay was used to detect the growth of human $\mathrm{T}$ cells at the indicated times $(24,48$, or $72 \mathrm{~h}$ ). As shown in Figure 1B, emodin inhibited the viability of human $\mathrm{T}$ cells in a dose- and time-dependent manner.

\section{Emodin induced significant apoptosis and DNA damage in human T cells}

To assess whether the cytotoxic effect of emodin was caused by apoptotic death, we evaluated the apoptosis of human $\mathrm{T}$ cells treated with emodin for $72 \mathrm{~h}$ using AO/EB staining. Compared with the control group, the percentage of apoptotic cells (yellow) was increased after emodin treatment, and necrotic cells were slightly increased (Figure 2A and 2B). These results were also supported by Annexin V/PI staining results (Figure 2C and 2D). Approximately $41.5 \%$ of the cells were in early apoptosis in the $100 \mu \mathrm{mol} / \mathrm{L}$ emodin-treated group compared with other groups (Figure 2C). As illustrated in Figure 2D, emodin induced a dose-dependent increase in apoptotic T cells.

Apoptosis is a prominent route of cell inactivation and is triggered by DNA damage. We used the comet assay to assess 
A

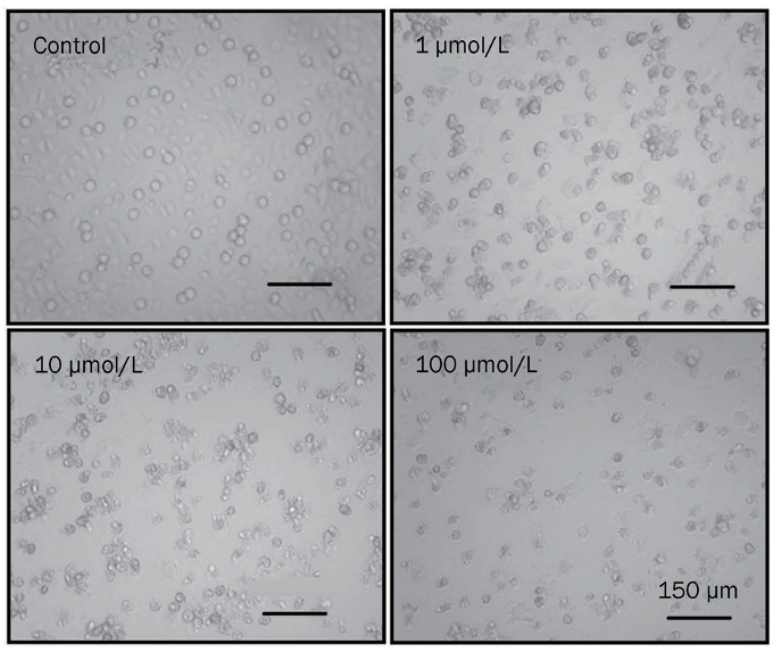

B

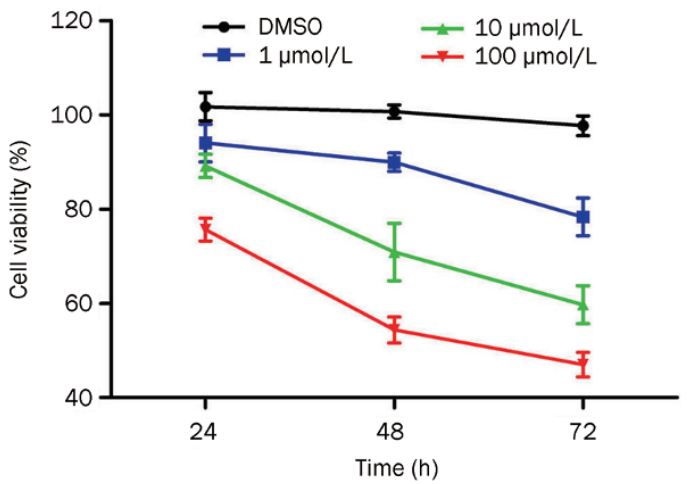

Figure 1. Effect of emodin treatment on the growth of human T cells. (A) Morphology changes of human T cells after treatment with emodin at different concentrations (1, 10, or $100 \mu \mathrm{mol} / \mathrm{L})$. (B) The inhibition of $\mathrm{T}$ cell growth induced by Emodin was detected by MTT assay. Data are represented as mean $\pm \mathrm{SD}$ from three independent experiments.

DNA damage accumulation. The difference in the tail moment of $\mathrm{T}$ cells treated with different concentrations of emodin was significant, indicating that DNA damage was involved in emodin-induced apoptosis in human T cells (Figure 2E and 2F).

\section{Emodin activated caspase cascades in human T cells}

Because caspase cascade activation is a key event in apoptosis pathways, we next assessed the effects of emodin on caspase activation in human $\mathrm{T}$ cells by Western blotting. The results showed that the quantities of the activated cleavage fragments of caspase- 9 and -4 increased after exposure to $100 \mu \mathrm{mol} / \mathrm{L}$ emodin for $72 \mathrm{~h}$, whereas the activated cleavage fragment of caspase-8 was not detected (Figure 3A-3D). We hypothesized that endoplasmic reticulum stress or the mitochondriamediated intrinsic apoptotic pathway might be involved in emodin-induced apoptosis, but the death receptor-mediated extrinsic apoptotic pathway might not be involved. In parallel with caspase- 9 and -4 activation, cleavage of the effector caspase- 3 was also increased (Figure 3A and 3E). Caspase-9, -4 , and -3 activation was also detected with the caspase activity assays, which supported the hypothesis that emodin activated caspase cascades via the intrinsic apoptosis pathway (Figure $3 \mathrm{~F}, 3 \mathrm{G}$, and $3 \mathrm{H})$.

\section{Emodin induced ER stress and intracellular free calcium elevation}

Several studies have previously reported that ER stress can lead to the proteolytic cleavage of caspase- 4 , which is localized to the cytoplasmic side of the ER membrane ${ }^{[15]}$. In our study, caspase- 4 was also activated by emodin treatment, suggesting that ER stress might be induced by emodin and involved in the apoptosis pathway. To determine whether emodin could induce ER stress, we investigated several crucial ER stress markers, including GRP78, ATF-4, XBP-1s, and CHOP. The expression of these ER stress markers in T cells was time-dependently induced after $100 \mu \mathrm{mol} / \mathrm{L}$ emodin treatment for $72 \mathrm{~h}$ (Figure 4A and 4B). Because the ER plays an important role in maintaining intracellular $\mathrm{Ca}^{2+}$ homeostasis, we speculated that emodin-induced ER stress might trigger $\mathrm{Ca}^{2+}$ release. Changes in intracellular free calcium were measured using Fluo-3-AM staining. The results showed more positively stained cells in emodin-treated $\mathrm{T}$ cells than in the control (Figure 4C), indicating intracellular $\mathrm{Ca}^{2+}$ overload after emodin treatment. The intracellular $\mathrm{Ca}^{2+}$ level was significantly increased along with the concentration of emodin, with the highest intracellular $\mathrm{Ca}^{2+}$ level in the $100 \mu \mathrm{mol} / \mathrm{L}$ emodin group (Figure 4D).

\section{Emodin disrupted the mitochondrial membrane potential and triggered Cyt $\mathrm{c}$ release}

The uptake of JC-1, a lipophilic cationic fluorescent dye absorbed by mitochondria, is positively correlated with the mitochondrial membrane potential ${ }^{[16]}$. An increase in green JC-1 can reflect the collapse of $\Delta \Psi \mathrm{m}$. As shown in Figure $5 \mathrm{~A}$ and $5 \mathrm{~B}$, a significant increase in green JC-1 was clearly observed in emodin-treated groups in a dose-dependent manner. In addition, the mitochondrial protein and cytosolic protein isolated from emodin-treated $\mathrm{T}$ cells were subjected to Western blotting. Equal protein loading was confirmed with COX IV immunodetection for mitochondrial protein and $\beta$-actin for cytosolic protein. The Western blotting results showed that the Bcl-2/Bax ratio in T cells, which reflects the maintenance of mitochondrial membrane stability, was significantly suppressed after $100 \mu \mathrm{mol} / \mathrm{L}$ emodin treatment for $72 \mathrm{~h}$ (Figure 5C and 5D). The release of Cyt $\mathrm{c}$ from mitochondria triggers the activation of caspase proteases and cell death by apoptosis. Our results also demonstrated that $100 \mu \mathrm{mol} / \mathrm{L}$ emodin increased cytosolic Cyt $\mathrm{c}$ and decreased mitochondrial Cyt c compared with the control group in a time-dependent manner (Figure 5E and 5F).

\section{Emodin treatment induced ROS production and oxidative stress in human $T$ cells}

We explored the upstream mechanisms leading to emodininduced ER stress and mitochondrial dysfunction using $\mathrm{DCFH}$, which is an intracellular probe used to examine the 
A
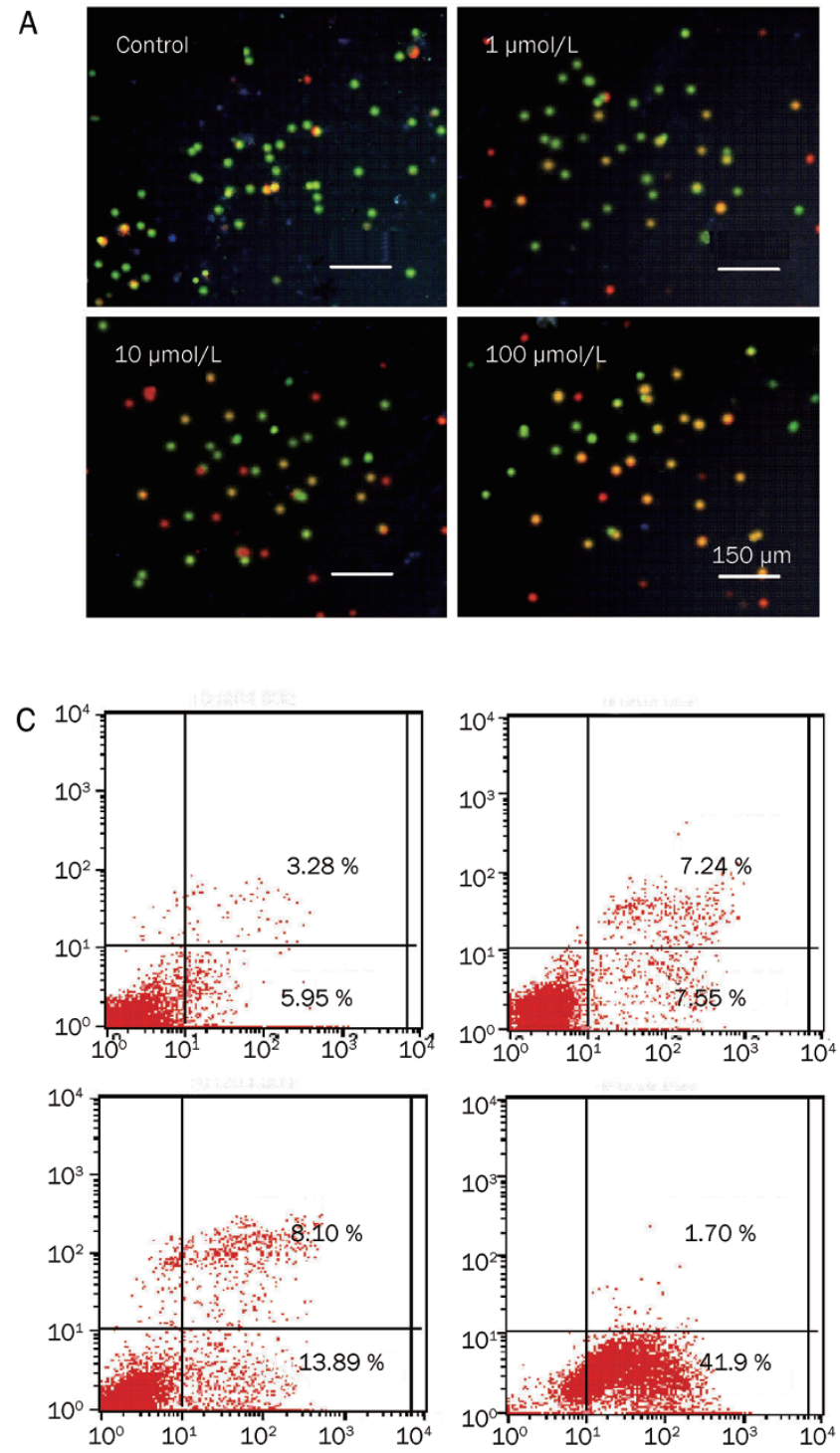

B

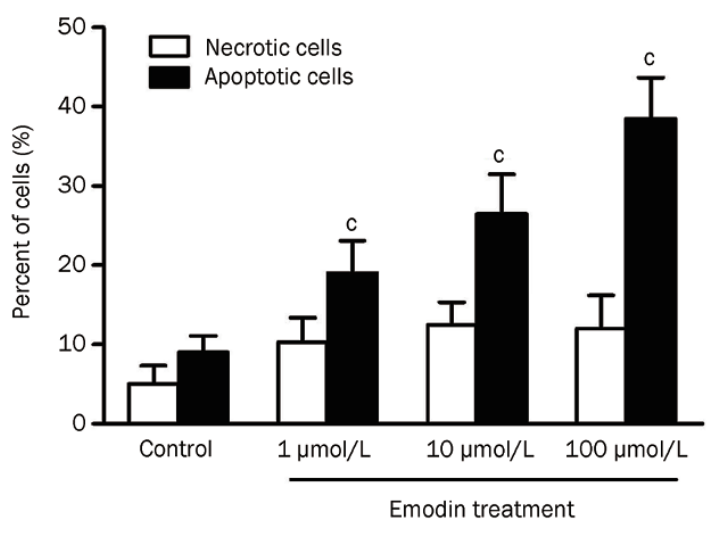

D

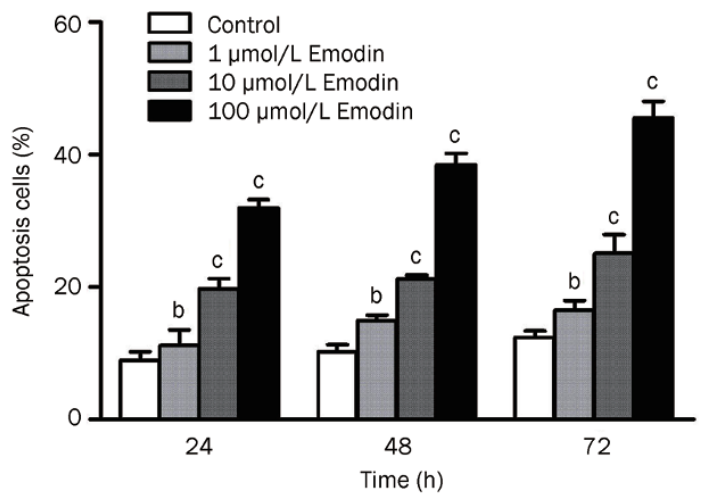

$\mathrm{F}$

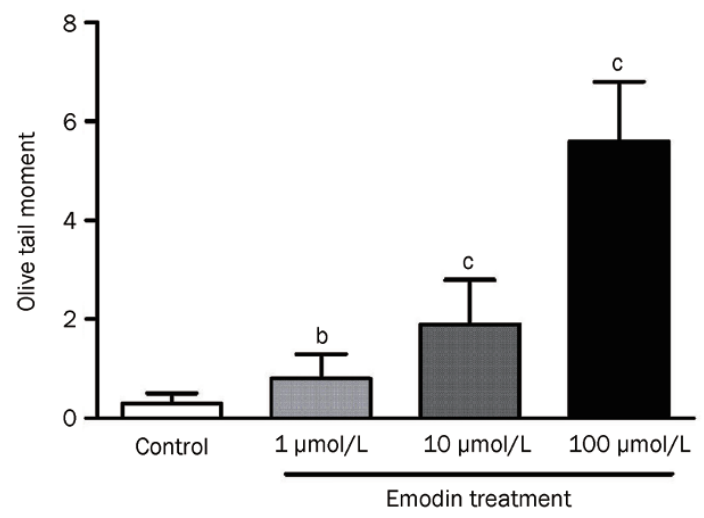

Figure 2. Emodin induced apoptosis and DNA damage of human T cells. (A) and (C) AO/EB double staining was used to detect cell apoptosis after emodin treatment at different concentrations (1, 10, or $100 \mu \mathrm{mol} / \mathrm{L})$. (B) and (D) Emodin-induced apoptosis of human T cells was detected by Annexin V/PI staining. (E) and (F) Comet assay was used to detect DNA damage. The results are given as mean \pm SD from three experiments. ${ }^{b} P<0.05,{ }^{c} P<0.01$ vs control groups. 
A

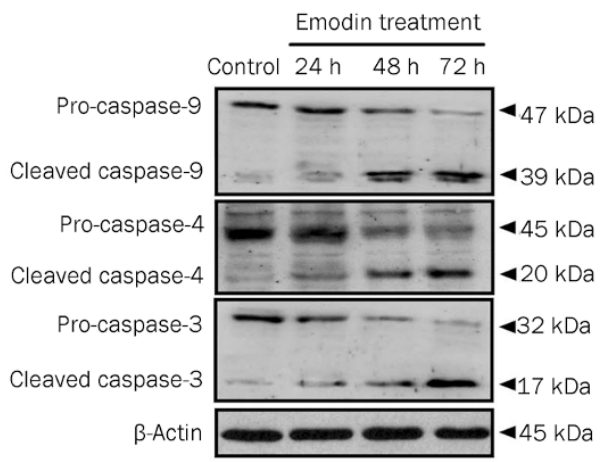

B

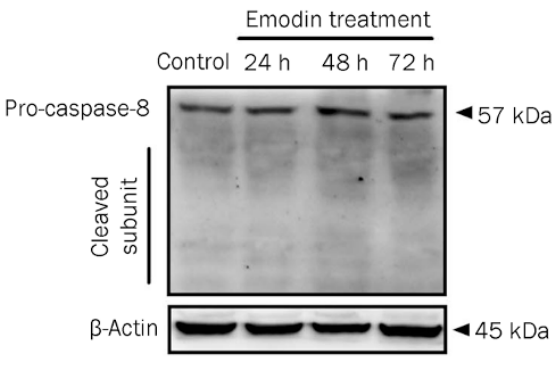

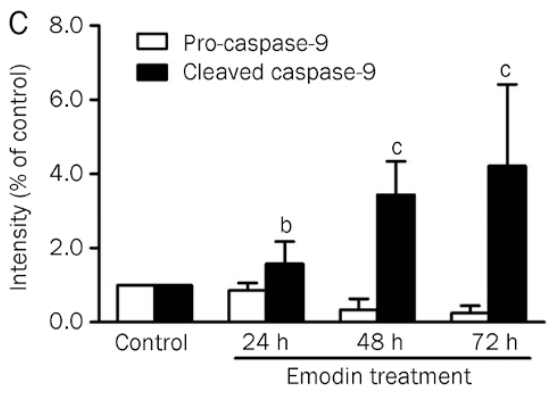

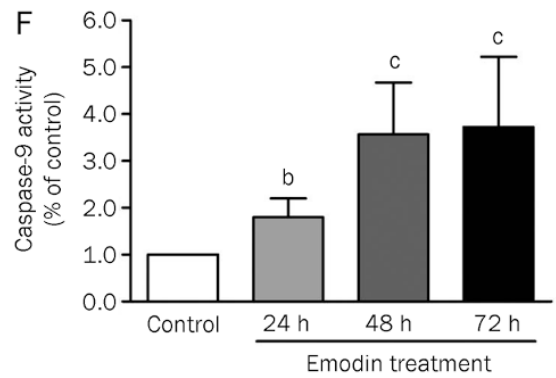

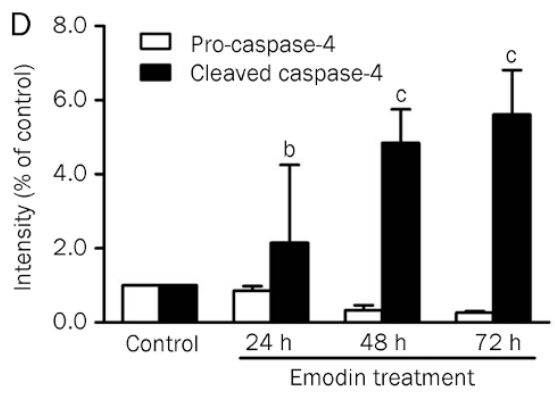
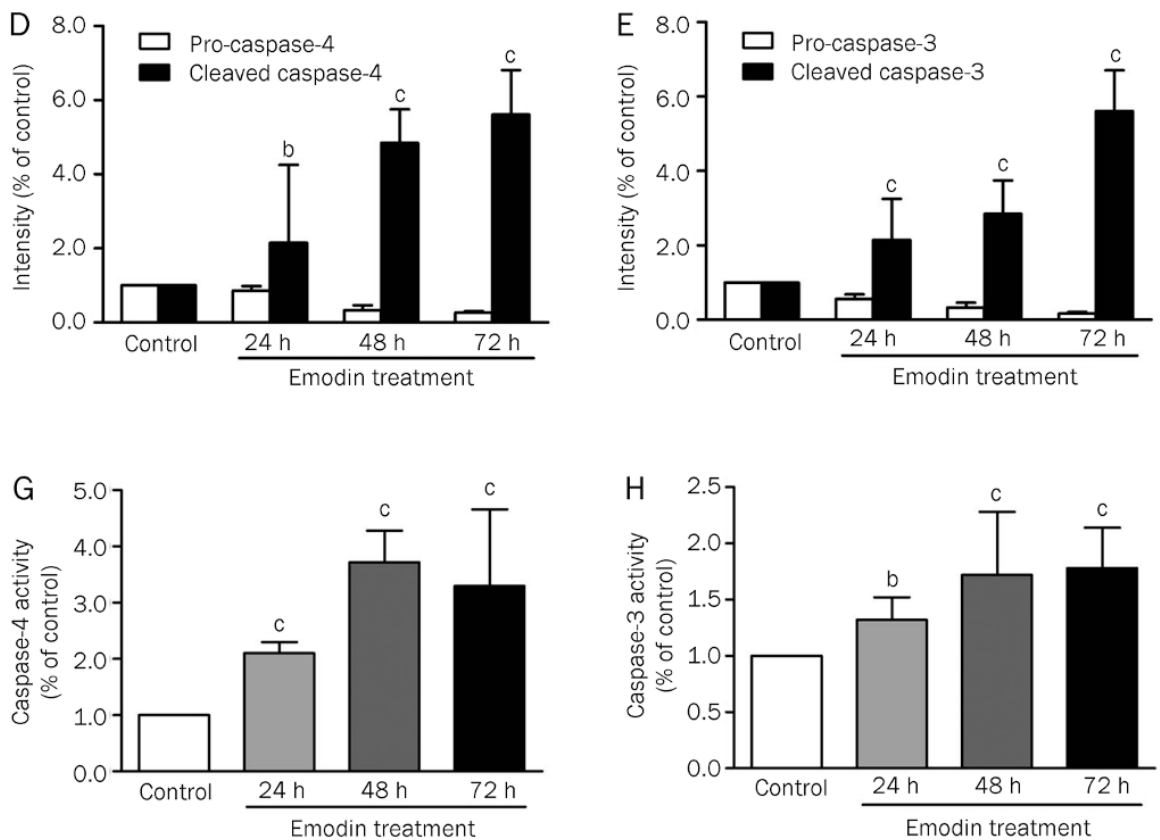

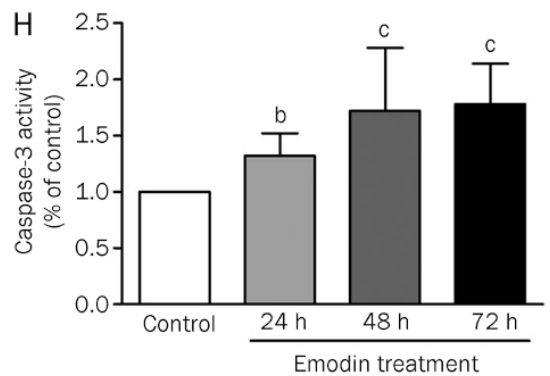

Figure 3. Expression and activity of caspases in human T cells after emodin treatment. (A) Pro- and cleaved caspase-9, -4 , and -3 of human T cells after emodin treatment with different doses were detected by Western blotting. (B) Pro- and cleaved caspase-8 were detected by Western blotting. (C), (D) and (E) The results of Western blotting were analyzed by Quantity One software. (F), $(G)$, and $(H)$ Activity of caspase- $-9,-4$, and -3 were detected by caspase activity assay. The results are given as mean \pm SD from three experiments. ${ }^{b} P<0.05,{ }^{\mathrm{c}} P<0.01$ vs control.

cellular ROS level. There was a significant dose-dependent increase in intracellular ROS levels in human T cells treated with emodin at $72 \mathrm{~h}$ (Figure 6A and 6B). In addition, we detected several crucial indicators of the redox potential in $\mathrm{T}$ cells treated with emodin, including an oxidative product (MDA) and anti-oxidative factors (SOD and GSH/GSSG). MDA and SOD are important markers that indicate a pro- and anti-oxidative status, respectively, and our results showed that SOD activity was significantly downregulated in $\mathrm{T}$ cells after emodin treatment, whereas MDA activity was upregulated (Figure 6C and 6D). The redox cycling of glutathione is believed to be a major intracellular antioxidant system that prevents the toxic accumulation of hydroperoxide. As shown in Figure 6E-6G, the GSH/GSSG ratio was decreased in T cells after emodin treatment. Taken together, these results indicated that emodin had a marked oxidative impact on the cel- lular redox status, which might be involved in ER stress and mitochondrial dysfunction-mediated apoptosis.

Removal of ROS with NAC attenuated emodin-induced ER stress, mitochondrial dysfunction and apoptosis in human $\mathrm{T}$ cells

To demonstrate the relationship between emodin-induced ROS production and ER stress, we coincubated T cells with $1 \mathrm{mmol} / \mathrm{L}$ exogenous NAC and $100 \mu \mathrm{mol} / \mathrm{L}$ emodin. After co-incubation with $1 \mathrm{mmol} / \mathrm{L}$ NAC for $72 \mathrm{~h}$, changes in the ROS, MDA and SOD levels caused by emodin treatment were abrogated (Figure 7A-7C). NAC also significantly attenuated emodin-induced $\mathrm{Ca}^{2+}$ overload (Figure 7D) and the activation of GRP78, ATF-4, XBP-1s, and CHOP (Figure 7G and 7H). In addition, we investigated the effect of ROS elimination with NAC on emodin-induced mitochondrial dysfunction. Exogenous NAC addition prevented the emodin-induced changes in 
A
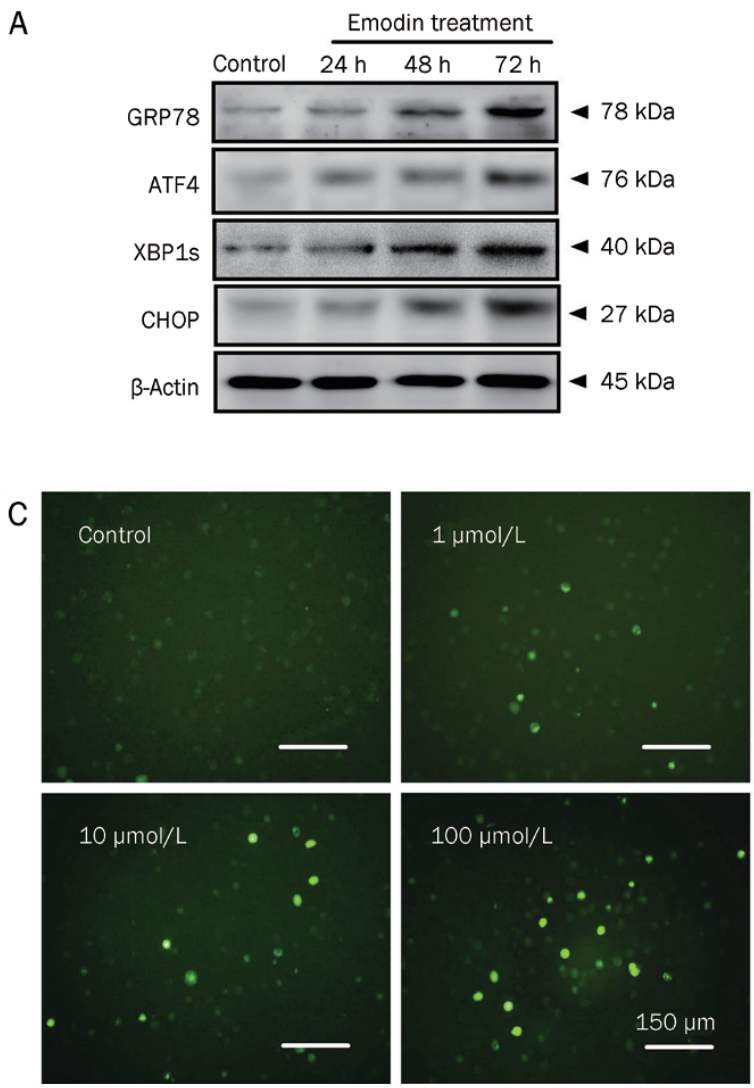

B

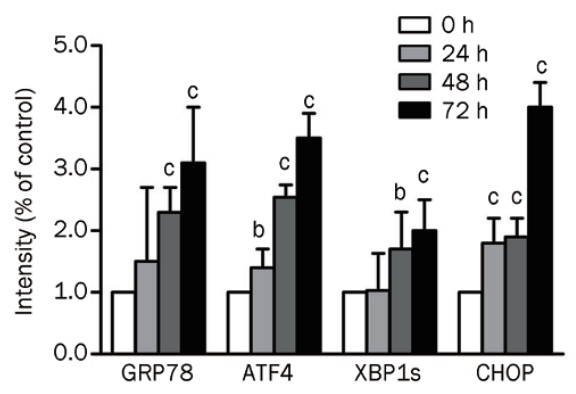

D

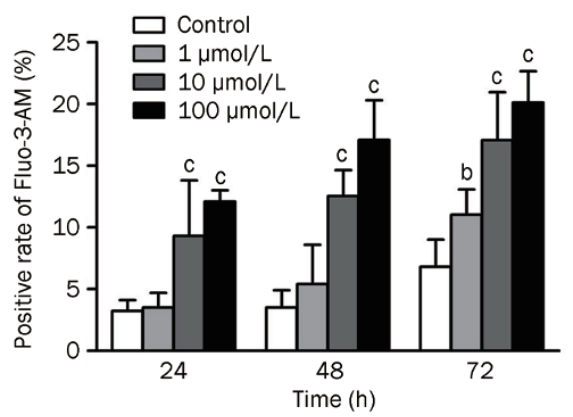

Figure 4. Endoplasmic reticulum stress and intracellular free calcium elevation of human T cells after emodin treatment. (A) Markers of ER stress including GRP78, ATF4, XBP1s and CHOP were detected by Western blotting. (B) The results of Western blotting were analyzed by Quantity One software. (C) Intracellular calcium measurement shown by Fluo-3-AM staining after emodin treatment for $72 \mathrm{~h}$. (D) Positive rate of Fluo-3-AM staining in different emodin treatment groups. The results are given as mean \pm SD from three experiments. ${ }^{b} P<0.05,{ }^{c} P<0.01$ vs control.

the mitochondrial membrane potential (Figure 7E, 7I and 7J). Furthermore, NAC simultaneously inhibited cell apoptosis (Figure 7F) and the activation of caspase-9, -4 , and -3 (Figure $7 \mathrm{~K}$ and $7 \mathrm{~L}$ ) induced by emodin. These results indicated that ROS played a significant role in emodin-induced ER stress and mitochondrial dysfunction in the $\mathrm{T}$ cell apoptosis process.

\section{Discussion}

Emodin exhibits a wide range of pharmacological effects, including anti-tumor ${ }^{[17]}$, anti-inflammatory ${ }^{[6]}$ and hepatic and renal protective activities ${ }^{[18]}$. Huang et a ${ }^{[19]}$ was the first to demonstrate the immunosuppressive effects of emodin, and our previous study also confirmed that emodin treatment attenuated skin allograft rejection and prolonged skin graft survival via stimulating serum IL-2 levels in skin transplantation models ${ }^{[8]}$. Similarly, Kuo et al demonstrated that emodin inhibited $\mathrm{T}$ cell proliferation via repressing IL-2 and IL-2R expression ${ }^{[20]}$. However, the effect and molecular mechanism of emodin on cellular apoptosis in human $\mathrm{T}$ cells remain unknown.

ROS are mediators of intracellular signaling cascades and can induce the collapse of the mitochondrial membrane potential, which can trigger a series of mitochondria-associated events, such as apoptosis ${ }^{[21]}$. Excessive ROS production may lead to oxidative stress, loss of cell function, and ultimately apoptosis or necrosis ${ }^{[22]}$. The molecular structure of emodin is similar to dimethyl naphthoquinone and mitochondrial ubiquinone, both of which have been reported to be able to induce ROS production ${ }^{[23,24]}$, and thus, we hypothesized that emodin may have the potential to induce ROS generation in $\mathrm{T}$ cells. In the present study, we demonstrated that emodininduced $\mathrm{T}$ cell apoptosis was associated with ROS generation, which triggered ER stress and mitochondrial damage in $T$ cells and activated the apoptosis pathway.

The disruption of ER homeostasis by ROS triggers cellular stress responses, including the unfolded protein response (UPR), an ER-specific stress response. GRP78, ATF-4, XBP$1 \mathrm{~s}$ and CHOP, which are found in the UPR signaling pathway, are important for the maintenance of normal cellular homeostasis ${ }^{[25-27]}$. The ER, as the major internal $\mathrm{Ca}^{2+}$ storage organelle, acts as a $\mathrm{Ca}^{2+}$ buffer that regulates $\mathrm{Ca}^{2+}$-dependent signaling in the cytosol. However, inappropriate activation of the UPR can lead to cellular dysfunction, and ultimately, cell death ${ }^{[28]}$. The results from our studies demonstrated that emodin-induced ROS can not only activate the ER stress markers GRP78, ATF-4, XBP-1s and CHOP but also disrupt the ER 
A
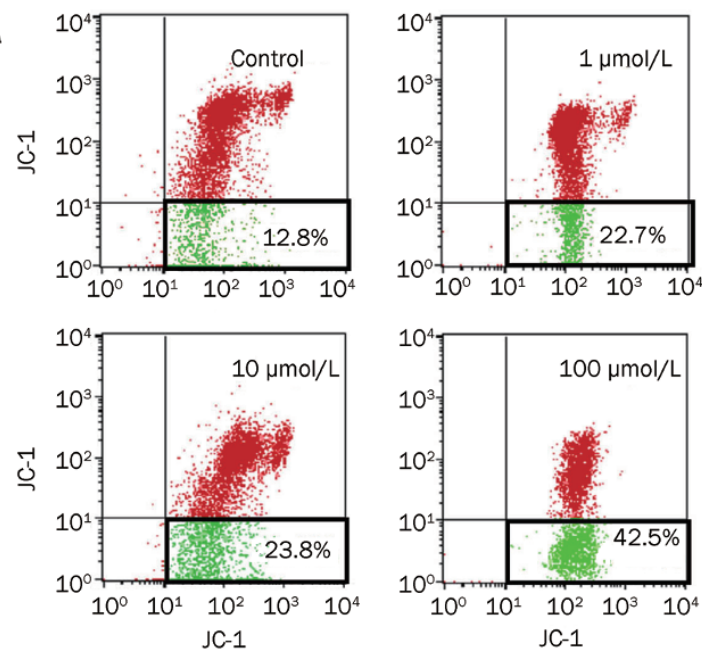

C

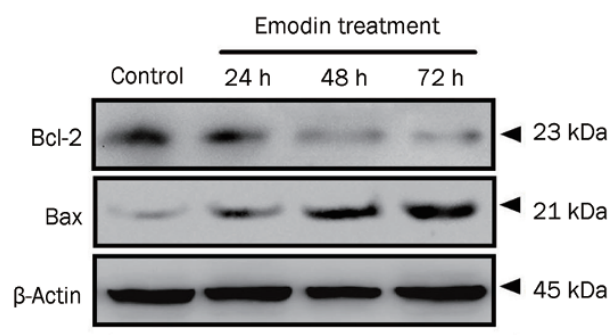

E

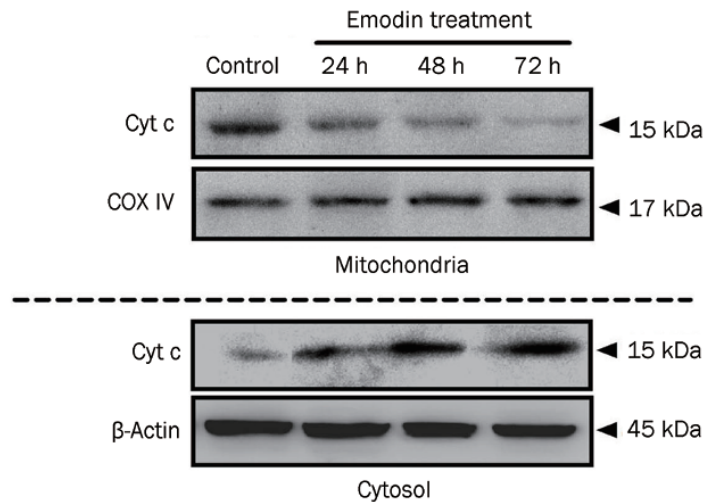

B
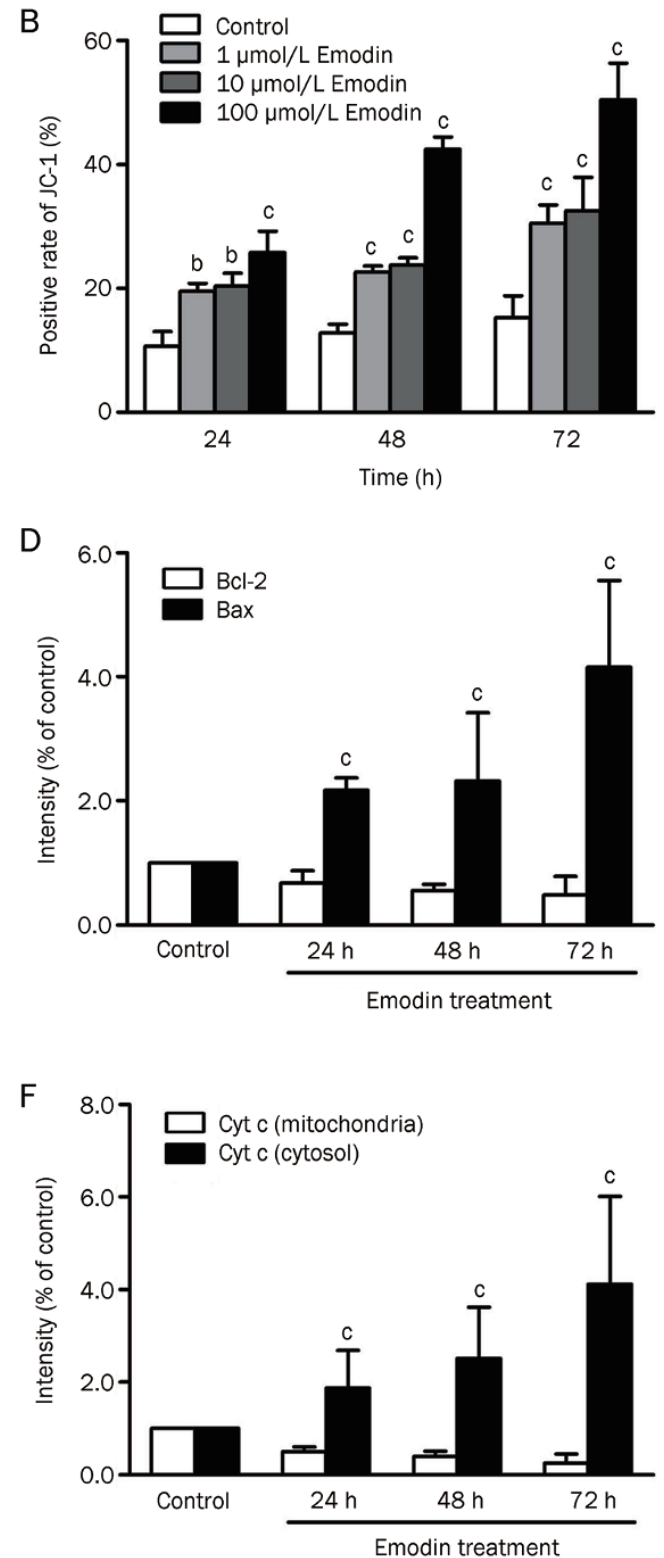

Figure 5. The disrupted mitochondrial membrane potential and Cyt c release of human T cells after emodin treatment. (A) JC-1 staining was used to detect $\Delta \Psi_{\mathrm{m}}$ level in human T cells treated by $100 \mu \mathrm{mol} / \mathrm{L}$ emodin for $72 \mathrm{~h}$. (B) Analysis of the $\Delta \Psi \mathrm{m}$ change in different comcentrations emodin treated T cells. (C) and (D) Alteration of Bcl-2 and Bax in T cells after $100 \mu \mathrm{mol} / \mathrm{L}$ emodin treatment for $24-72 \mathrm{~h}$. (E) and (F) Cyt c release from mitochondria to cytosol in T cells after $100 \mu \mathrm{mol} / \mathrm{L}$ emodin treatment for $24-72 \mathrm{~h}$. The results are given as mean \pm SD from three experiments. ${ }^{\mathrm{b}} \mathrm{P}<0.05,{ }^{\mathrm{C}} \mathrm{P}<0.01 \mathrm{vs}$ control groups.

membrane and trigger $\mathrm{Ca}^{2+}$ release in human $\mathrm{T}$ cells (Figure 4). In contrast, the removal of ROS with the antioxidant NAC attenuated the emodin-induced activation of UPR and $\mathrm{Ca}^{2+}$ release.

Mitochondria and the ER constitute the endomembrane networks and interact with each other physically and functionally. Mitochondria and the ER are major internal $\mathrm{Ca}^{2+}$ storage organelles, and the transfer of $\mathrm{Ca}^{2+}$ from the ER to mitochondria through this connection is one of the critical pathways in regulating cell functions. Calcium uptake into the mitochondria is driven by the consumption of the mitochondrial mem- brane potential. Several reports showed that emodin induced ER stress and mitochondrial dysfunction in cancer cells ${ }^{[15,29,30]}$. To investigate whether mitochondrial function was affected by emodin-induced ER stress in human T cells, we evaluated alterations in the mitochondrial membrane potential and several crucial proteins that maintain mitochondrial function. Our results confirmed that emodin significantly decreased the mitochondrial membrane potential. Furthermore, the ratio of Bcl-2 and Bax, which represents mitochondrial function, was also decreased in $\mathrm{T}$ cells after emodin treatment. As a result, the release of Cyt $\mathrm{c}$ and the activation of caspase proteases 
A

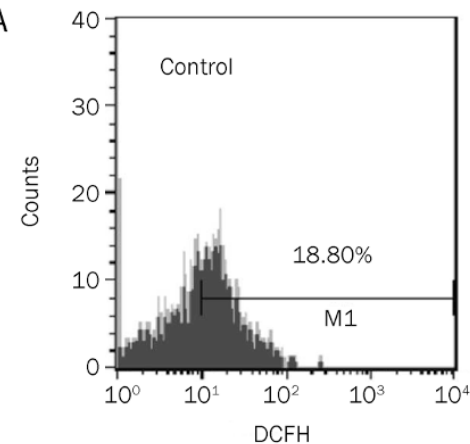

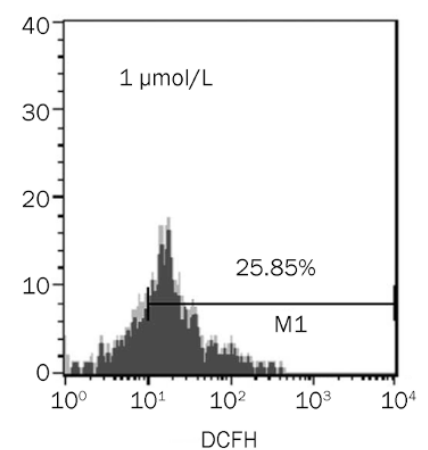

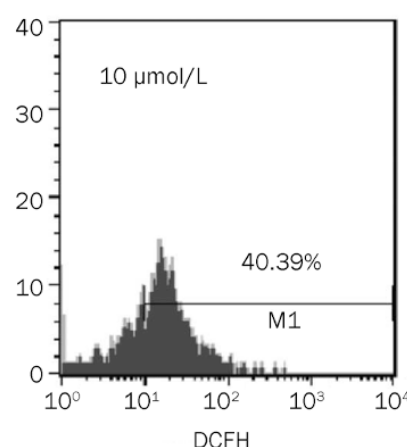

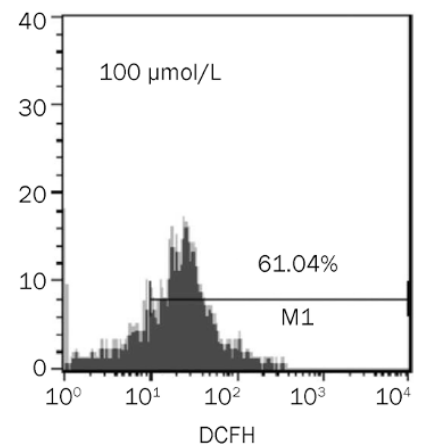
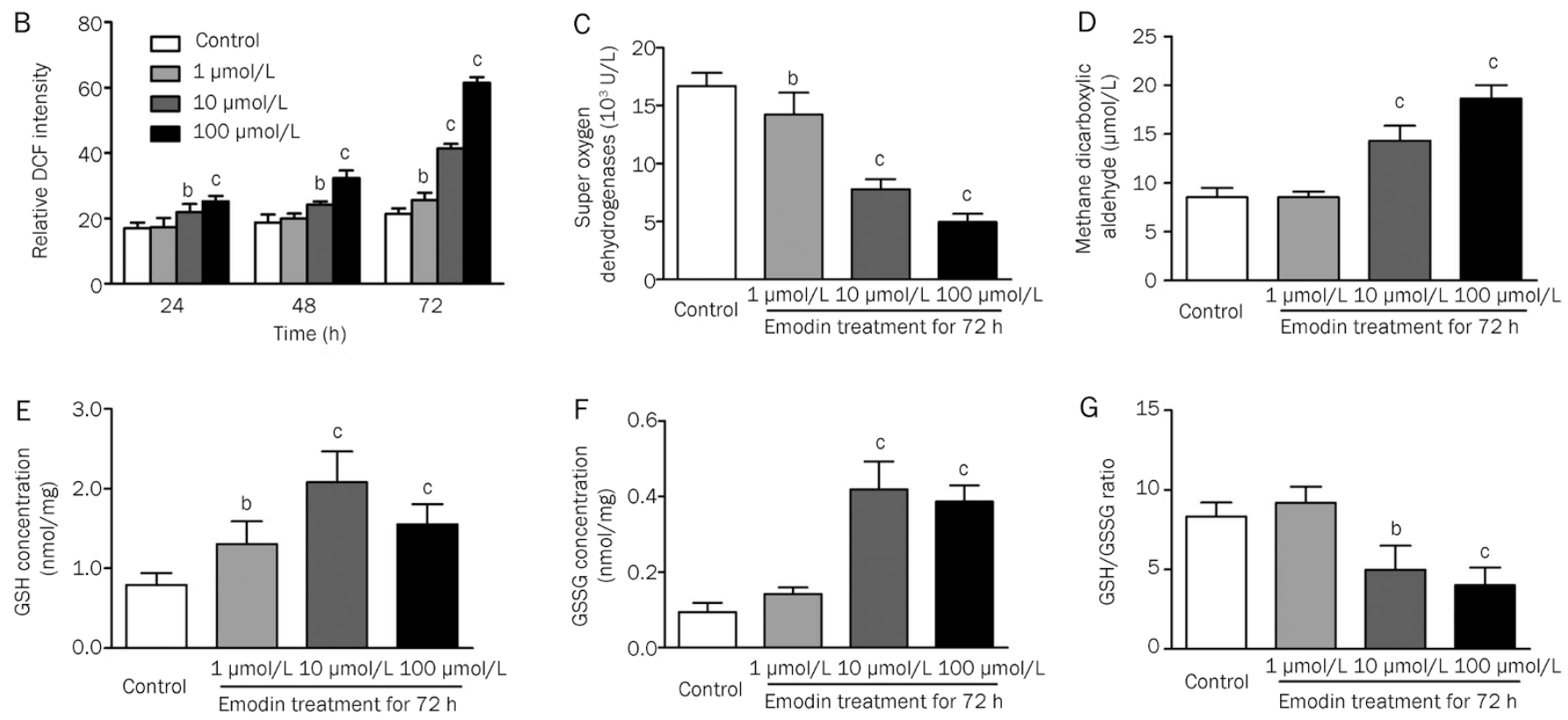

Figure 6. Emodin significantly induced ROS generation in human T cells. (A) DCFH staining was used to detect ROS level in human T cells treated by $100 \mu \mathrm{mol} / \mathrm{L}$ emodin for $72 \mathrm{~h}$. (B) Analysis of ROS changes in different emodin treated T cells. (C) Effect of emodin on intracellular SOD activity. (D) Effect of emodin on intracellular MDA activity. (E) Effect of emodin on intracellular GSH level. (F) Effect of emodin on intracellular GSSG level. (G) Analysis of the GSH/GSSG ratio. The results are given as mean \pm SD from three experiments. ${ }^{b} P<0.05,{ }^{c} P<0.01$ vs control groups.

caused by mitochondrial dysfunction eventually trigger cellular apoptosis. As a ROS scavenger, the antioxidant NAC can suppress emodin-induced mitochondrial dysfunction and attenuate apoptosis.

In conclusion, our results demonstrate that emodin-induced apoptosis in human T cells is mediated by the activation of ER stress and the dysfunction of mitochondria and requires ROS generation (Figure 8). Our study thus provides a rationale for the development of emodin as an immunosuppressive agent against $\mathrm{T}$ cell-mediated autoimmune disease.

\section{Acknowledgements}

This project was financially supported by grants from the National Natural Science Foundation of China (№ 30872482, 81072051, 81201549 and 81272644) and the Scientific Research Project of Shaanxi Administration of Traditional Chinese Medicine (No 2003135).

\section{Author contribution}

Chang LIU, Nai-ying SHEN, and Kai QU designed the research; Nai-ying SHEN, Hai-bo SU, Ji-chao WEI, Ming-hui TAI, and Fan-di MENG performed the research; Lei ZHOU and Yue-lang ZHANG analyzed the data; Kai QU and Xin-sen XU wrote the paper.

\section{References}

1 Bettini M, Vignali DA. Regulatory T cells and inhibitory cytokines in autoimmunity. Curr Opin Immunol 2009; 21: 612-8.

2 Migita K, Origuchi T, Kawabe Y, Tominaga M, Ida H, Kawakami A, et al. FK506 markedly enhances apoptosis of antigen-stimulated peripheral T cells by down-regulation of Bcl-x. Transplantation 1999; 68: 1018-23.

3 Antunes RF, Brandao C, Carvalho G, Girao C, Arosa FA. Red blood cells carry out $\mathrm{T}$ cell growth and survival bioactivities that are sensitive to cyclosporine A. Cell Mol Life Sci 2009; 66: 3387-98.

4 Hester J, Schiopu A, Nadig SN, Wood KJ. Low-dose rapamycin 
A

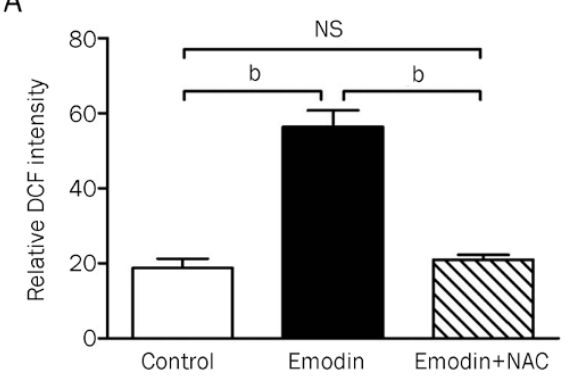

D

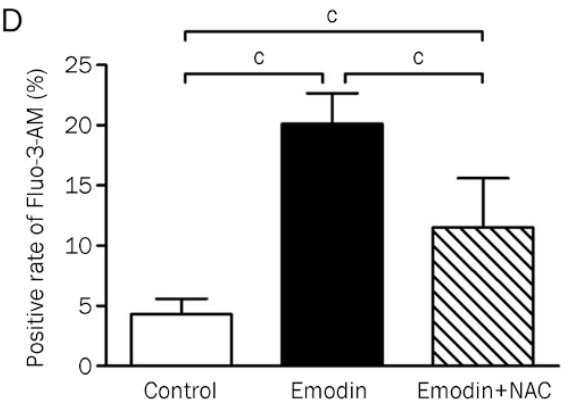

G
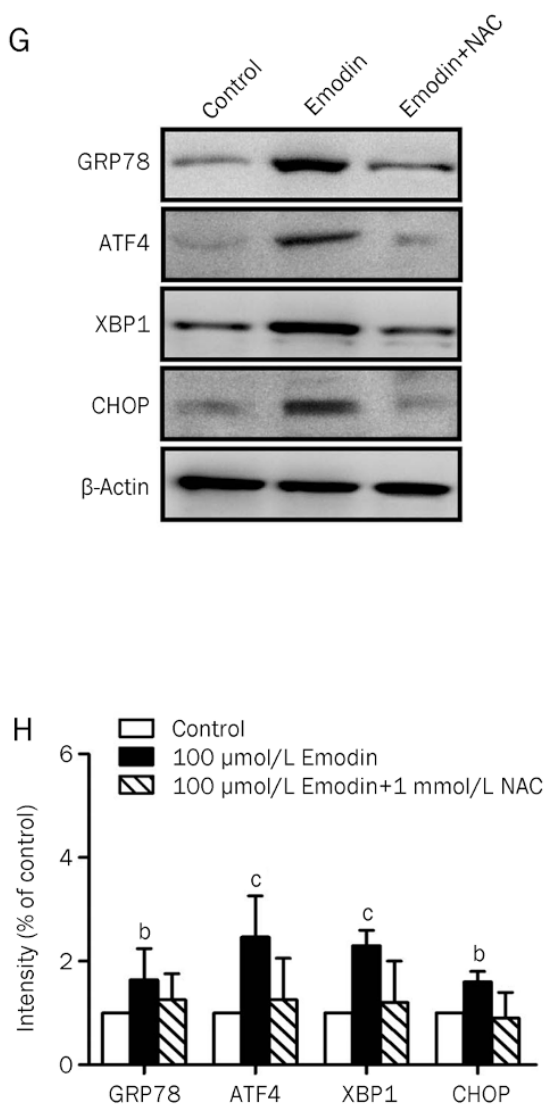

B

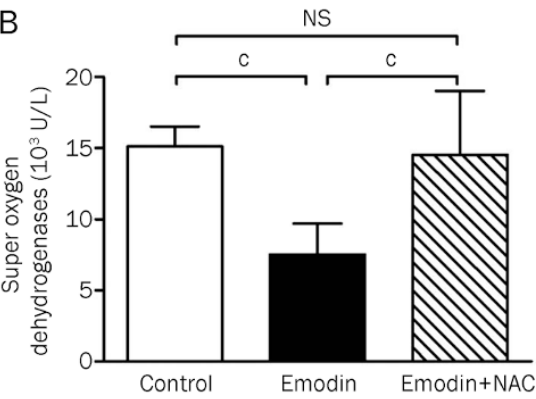

E

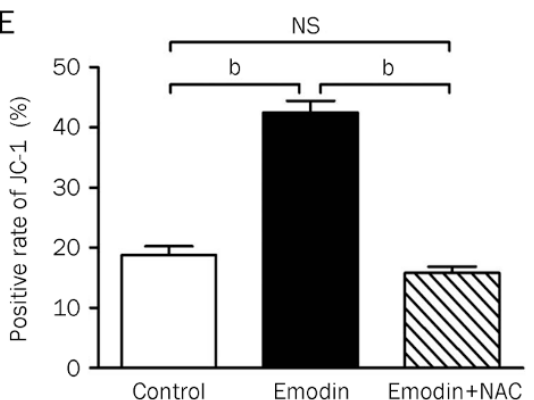

।

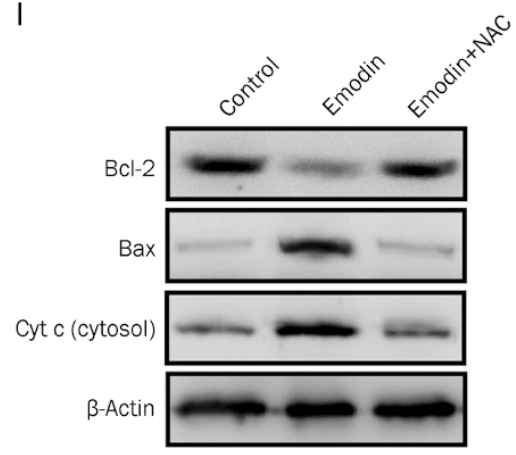

C

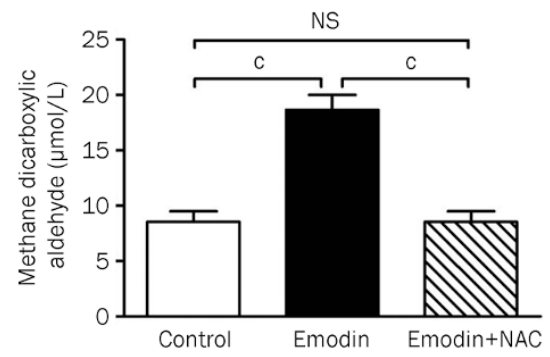

F

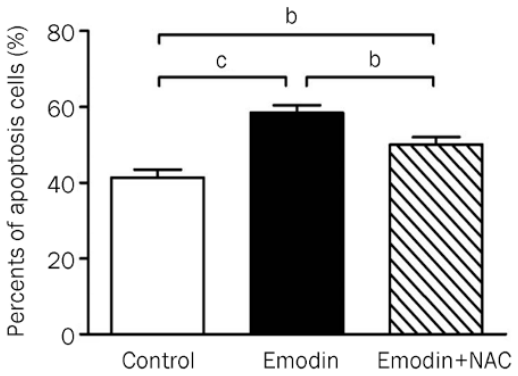

K

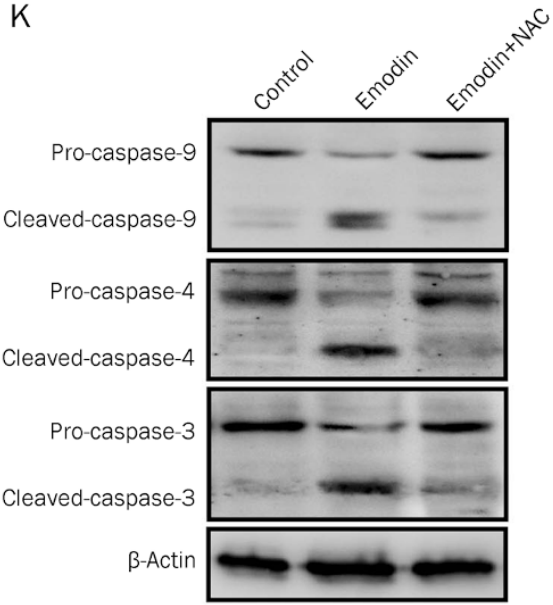

L

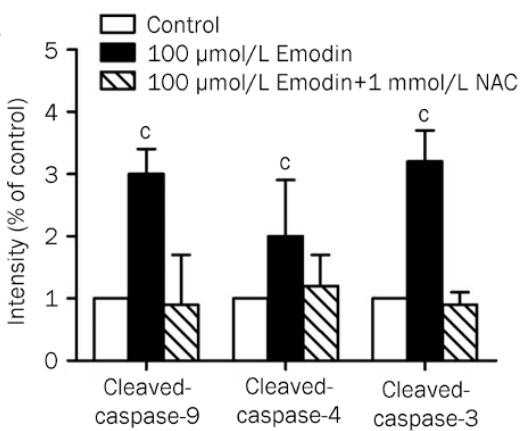

Figure 7. Effect of NAC-replenishing on emodin-induced ER stress, mitochondrial dysfunction and apoptosis in T cells. Replenishing of $20 \mu$ mol/L exogenous NAC significangly reduced the ROS (A) and MDA (C) production induced by $100 \mu \mathrm{mol} / \mathrm{L}$ emodin, and elevated antioxidant SOD level (B). NAC replenishing also rescued $\mathrm{ER}$ stress $(\mathrm{G}$ and $\mathrm{H}), \mathrm{Ca}^{2+}$ release $(\mathrm{D})$, disruption of $\Delta \Psi_{\mathrm{m}}(\mathrm{E})$, mitochondrial dysfunction and cytochrome $\mathrm{C}$ release $(\mathrm{I}$ and $\mathrm{J}$ ) induced by emodin, which finally inactivated caspases ( $K$ and $L$ ), and reduced apoptosis of $T$ cells $(F)$. The results are given as mean $\pm S D$ from three experiments. ${ }^{\mathrm{b}} \mathrm{P}<0.05,{ }^{\mathrm{c}} \mathrm{P}<0.01$ vs control groups.

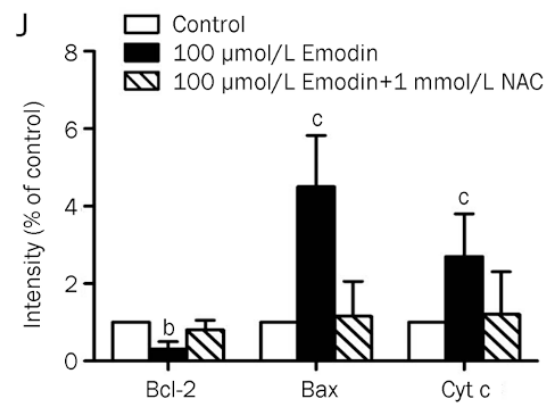




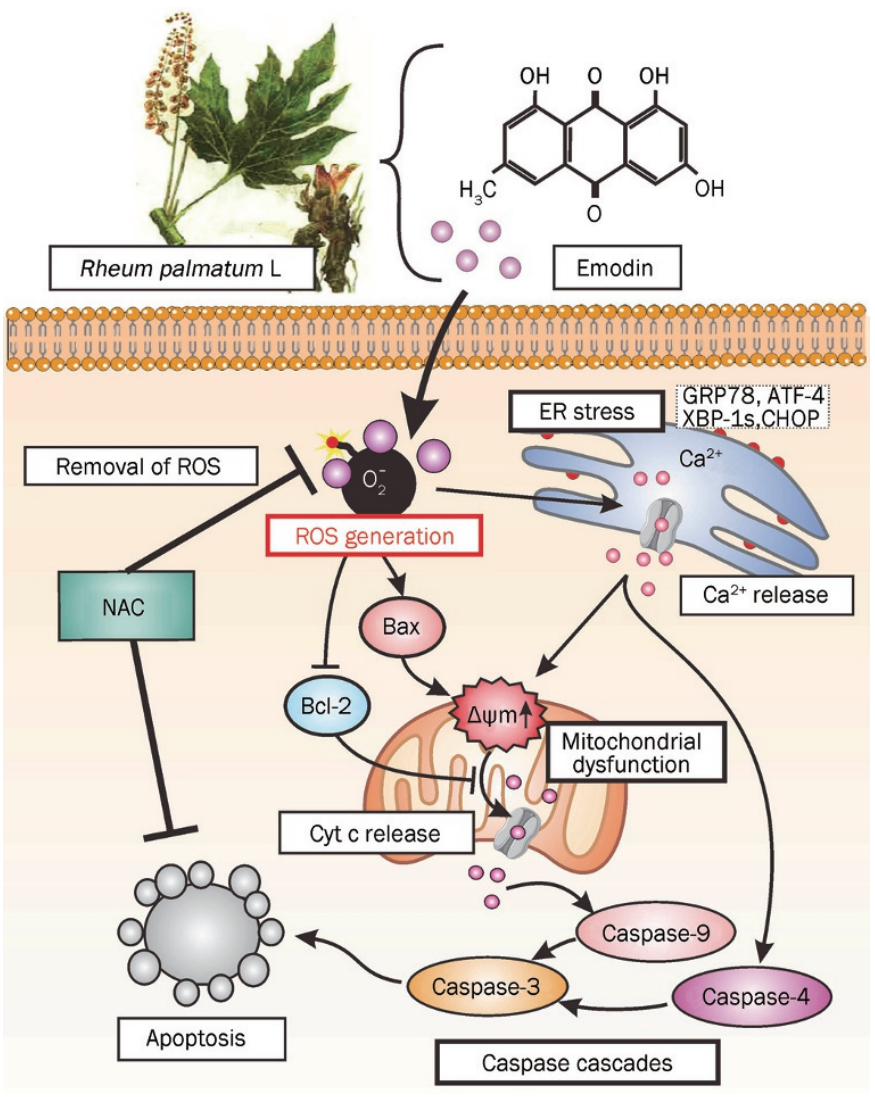

Figure 8. Overview of the ROS-mediated ER stress and mitochondrial dysfunction in emodin-induced apoptosis in human T cells. Treatment of T cells with emodin results in ER stress by upregulating GRP78, ATF-4, XBP$1 \mathrm{~s}$, and CHOP. As the key transcription factors induced by ER stress, they would trigger the $\mathrm{Ca}^{2+}$ release. Emodin also reduces the mitochondrial membrane potential and $\mathrm{Bcl}-2 / \mathrm{Bax}$ ratio, contributing to the activation of caspase- $4,-9$, and -3 and apoptosis progression. The emodin-induced ER stress and mitochondrial dysfunction require the ROS generation, and on the contrary, antioxidant NAC suppresses emodin-induced apoptosis in human T cells.

treatment increases the ability of human regulatory $T$ cells to inhibit transplant arteriosclerosis in vivo. Am J Transplant 2012; 12 : 2008-16.

5 Ding Y, Zhao L, Mei H, Zhang SL, Huang ZH, Duan YY, et al. Exploration of Emodin to treat alpha-naphthylisothiocyanate-induced cholestatic hepatitis via anti-inflammatory pathway. Eur J Pharmacol 2008; 590: 377-86.

6 Basu S, Ghosh A, Hazra B. Evaluation of the antibacterial activity of Ventilago madraspatana Gaertn, Rubia cordifolia Linn and Lantana camara Linn: isolation of emodin and physcion as active antibacterial agents. Phytother Res 2005; 19: 888-94.

7 Huang HC, Chang JH, Tung SF, Wu RT, Foegh ML, Chu SH. Immunosuppressive effect of emodin, a free radical generator. Eur J Pharmacol 1992; 211: 359-64.

8 Liu YX, Shen NY, Liu C, Lv Y. Immunosuppressive effects of emodin: an in vivo and in vitro study. Transplant Proc 2009; 41: 1837-9.

9 Chen F, Ni Y, Ye Y, Sun H, Li X, Xu S. Stephanthraniline A inhibits the proliferation and activation of $\mathrm{T}$ cells in vitro and in vivo. Eur $\mathrm{J}$ Pharmacol 2012; 685: 186-97.
10 Zhang XR, Zhou WX, Zhang YX, Qi CH, Yan H, Wang ZF, et al. Macrophages, rather than $T$ and $B$ cells are principal immunostimulatory target cells of Lycium barbarum $L$ polysaccharide LBPF4OL. J Ethnopharmacol 2011; 136: 465-72.

11 Mao YX, Chen YJ, Ge Y, Ma HB, Yu JF, Wu HY, et al. Recombinant human B7-H4 expressed in Escherichia coli inhibits T lymphocyte proliferation and IL-2 secretion in vitro. Acta Pharmacol Sin 2006; 27: 741-6.

12 Qian J, Jiang F, Wang B, Yu Y, Zhang X, Yin Z, et al. Ophiopogonin $D$ prevents $\mathrm{H} 2 \mathrm{O} 2$-induced injury in primary human umbilical vein endothelial cells. J Ethnopharmacol 2010; 128: 438-45.

13 He J, Huang B, Ban X, Tian J, Zhu L, Wang Y. In vitro and in vivo antioxidant activity of the ethanolic extract from Meconopsis quintuplinervia. J Ethnopharmacol 2012; 141: 104-10.

14 Qu K, Xu X, Liu C, Wu Q, Wei J, Meng F, et al. Negative regulation of transcription factor FoxM1 by p53 enhances oxaliplatin-induced senescence in hepatocellular carcinoma. Cancer Lett 2013; 331: 105-14.

15 Hsia TC, Yang JS, Chen GW, Chiu TH, Lu HF, Yang MD, et al. The roles of endoplasmic reticulum stress and $\mathrm{Ca} 2+$ on rhein-induced apoptosis in A-549 human lung cancer cells. Anticancer Res 2009; 29: 309-18.

16 He XL, Zhang P, Dong XZ, Yang MH, Chen SL, Bi MG. JR6, a new compound isolated from Justicia procumbens, induces apoptosis in human bladder cancer EJ cells through caspase-dependent pathway. J Ethnopharmacol 2012; 144: 284-92.

17 Wang W, Bai Z, Zhang F, Wang C, Yuan Y, Shao J. Synthesis and biological activity evaluation of emodin quaternary ammonium salt derivatives as potential anticancer agents. Eur J Med Chem 2012; 56: 320-31.

18 Imanishi Y, Maeda N, Otogawa K, Seki S, Matsui H, Kawada N, et al. Herb medicine Inchin-ko-to (TJ-135) regulates PDGF-BB-dependent signaling pathways of hepatic stellate cells in primary culture and attenuates development of liver fibrosis induced by thioacetamide administration in rats. J Hepatol 2004; 41: 242-50.

19 Huang HC, Chu SH, Chao PD. Vasorelaxants from Chinese herbs, emodin and scoparone, possess immunosuppressive properties. Eur J Pharmacol 1991; 198: 211-3.

20 Kuo YC, Meng HC, Tsai WJ. Regulation of cell proliferation, inflammatory cytokine production and calcium mobilization in primary human T lymphocytes by emodin from Polygonum hypoleucum Ohwi. Inflamm Res 2001; 50: 73-82.

21 Hildeman DA, Mitchell T, Kappler J, Marrack P. T cell apoptosis and reactive oxygen species. J Clin Invest 2003; 111: 575-81.

22 Ray PD, Huang BW, Tsuji Y. Reactive oxygen species (ROS) homeostasis and redox regulation in cellular signaling. Cell Signal 2012; 24: 981-90.

23 Teixeira HD, Schumacher RI, Meneghini R. Lower intracellular hydrogen peroxide levels in cells overexpressing CuZn-superoxide dismutase. Proc Natl Acad Sci U S A 1998; 95: 7872-5.

24 Kwong LK, Sohal RS. Substrate and site specificity of hydrogen peroxide generation in mouse mitochondria. Arch Biochem Biophys 1998; 350: 118-26.

25 Feldman DE, Chauhan V, Koong AC. The unfolded protein response: a novel component of the hypoxic stress response in tumors. Mol Cancer Res 2005; 3: 597-605.

26 Oyadomari S, Mori M. Roles of CHOP/GADD153 in endoplasmic reticulum stress. Cell Death Differ 2004; 11: 381-9.

27 Ohoka N, Yoshii S, Hattori T, Onozaki K, Hayashi H. TRB3, a novel ER stress-inducible gene, is induced via ATF4-CHOP pathway and is involved in cell death. EMBO J 2005; 24: 1243-55. 
28 Morishima N, Nakanishi K, Takenouchi H, Shibata T, Yasuhiko Y. An endoplasmic reticulum stress-specific caspase cascade in apoptosis. Cytochrome c-independent activation of caspase- 9 by caspase- 12 . J Biol Chem 2002; 277: 34287-94.

29 Lin SY, Lai WW, Ho CC, Yu FS, Chen GW, Yang JS, et al. Emodin induces apoptosis of human tongue squamous cancer SCC-4 cells through reactive oxygen species and mitochondria-dependent pathways. Anticancer Res 2009; 29: 327-35.

30 Lin ML, Chen SS, Lu YC, Liang RY, Ho YT, Yang CY, et al. Rhein induces apoptosis through induction of endoplasmic reticulum stress and $\mathrm{Ca}^{2+}$-dependent mitochondrial death pathway in human nasopharyngeal carcinoma cells. Anticancer Res 2007; 27: 3313-22. 